\title{
Influence of Organoclay Structure on Nanostructured Materials Based on Eva
}

\author{
Gisele C. V. Iulianelli1 ${ }^{*}$, Pedro José Oliveira Sebastião ${ }^{2,3}$, Maria Inês B. Tavares ${ }^{1}$, \\ Fernanda Abbate dos Santos ${ }^{1}$ \\ ${ }^{1}$ Instituto de Macromoléculas Professora Eloisa Mano da Universidade Federal do Rio de Janeiro (IMA/UFRJ), \\ Centro de Tecnologia, Bloco J, Ilha do Fundão, Rio de Janeiro, RJ CEP: 21941-598, Brazil \\ ${ }^{2}$ Condensed Matter Physics Centre, University of Lisbon, Lisbon, Portugal \\ ${ }^{3}$ Departamento de Física, Instituto Superior Técnico, Technical University of Lisbon, Lisbon, Portugal \\ Email: "gisele@ima.ufri.br
}

Received 28 July 2015; accepted 13 October 2015; published 16 October 2015

Copyright (C) 2015 by authors and Scientific Research Publishing Inc.

This work is licensed under the Creative Commons Attribution International License (CC BY).

http://creativecommons.org/licenses/by/4.0/

(c) (i) Open Access

\section{Abstract}

This article reports the preparation of a series of EVA nanocomposites employing solution casting methods using different types of organo-modified montmorillonite clay. The effect of the organoclay type on the structural organization and thermal behavior of EVA nanostructured materials were systematically investigated. Regarding thermal behavior, the thermogravimetric analysis showed that the nanocomposites presented a slight decrease in thermal degradation temperature compared to EVA, while differential scanning calorimetry, in general, did not show a significant change in the thermal transition temperatures such as glass transition, melting temperature and crystallization temperature of the nanocomposites, regardless of the type and proportion of organoclay in the systems. With respect to structural aspect, the X-ray diffractograms showed that all systems presented a heterogeneous distribution of the nanoparticles, containing part intercalated. Nuclear magnetic resonance relaxometry data provided complementary information for the $\mathrm{X}$-ray results, showing that the EVA systems containing $5 \mathrm{wt} \%$ of both studied organoclays presented a mixture of intercalated and exfoliated structures, evidencing that there was a surface interaction between polymer chains and clay lamellae.

\section{Keywords}

EVA, Nanocomposites, NMR, Relaxometry

\footnotetext{
${ }^{*}$ Corresponding author.
}

How to cite this paper: Iulianelli, G.C.V., Sebastião, P.J.O., Tavares, M.I.B. and dos Santos, F.A. (2015) Influence of Organoclay Structure on Nanostructured Materials Based on Eva. Materials Sciences and Applications, 6, 860-868. 


\section{Introduction}

Polymer nanocomposites are extremely attractive in both science and industry because these materials often exhibit better physical and mechanical properties than isolated polymers, such as increased modulus, reduced gas permeability and enhanced thermal stability, among others [1]-[5]. One of the best advantages of nanocomposites is related to the quantity of nanoparticles added to the polymer matrix compared to the normal composite. In a conventional composite, the quantity of filler must be as high as possible (i.e., over $30 \mathrm{wt} \%$ ), whereas in a polymer nanocomposite the quantity of filler varies from 1 to $5 \mathrm{wt} \%$ or less than $1 \%$, because the nanometric dimensions of the particles provide a larger surface area in relation to volume, generally causing good improvement in the polymer's properties [6].

When polymer-layered silicate nanocomposites (PLSN) are prepared, some structure types are obtained: intercalated nanocomposites, where the polymer chains are intercalated in the galleries, but the periodicity of the clay lamellae is still intact; delaminated or exfoliated nanocomposites, where the lamellae are far apart from each other so that the periodicity of this layer arrangement is totally lost, allowing that delaminated silicates are uniformly dispersed in the matrix [7] [8]; or a mix of both, which is more common, since the dispersion and distribution of nanoparticles are not straightforward. One important point to obtain good nanomaterials is the polymer/nanoparticle pair, and consequently the nanoparticles' dispersion in the polymer matrix [9], which depends on the chemical structure of the polymer and nanoparticle and the mixing process as well. For PLSN, the properties are directly correlated with the exfoliated/intercalated regions, which in turn result from the dispersion/distribution of the nanoclay layers in the polymeric matrix [10].

Several polymer nanocomposites using many types of matrixes have been studied, including ethylene-covinyl acetate (EVA), polyethylene (PE), polypropylene (PP) polyamide-6 (Ny6) and polystyrene (PS) [11]-[15]. Among them, nanocomposites based on EVA are of great interest, mainly because EVA/clay nanocomposites can be easily prepared since EVA contains a certain quantity of the polar group, vinyl acetate, which can effectively interact better with clays [16].

In this study, the first objective was to obtain hybrid nanocomposites based on EVA prepared by the solution casting method containing two organo-modified montmorillonite clays (OMMT) with different intercalating agents. The nanomaterials prepared were evaluated and compared according to the interaction forces between nanoparticles and EVA matrix.

The use of modified montmorillonites containing intercalating agents aims to promote better dispersion and distribution of nanoparticles in the polymer matrix, since the intermolecular interactions are strong enough for that.

The second objective was to characterize the nanocomposites obtained employing thermogravimetric analysis (TGA), differential scanning calorimetry (DSC), X-ray diffraction and mainly nuclear magnetic resonance relaxometry, using the spin-lattice relaxation time parameter $\left(\mathrm{T}_{1}\right)$, which is an innovative and advanced method to determine the degree of clay intercalation and/or exfoliation in polymeric nanocomposites [17] [18].

The proton spin-lattice relaxation time has been used for Tavares group because it is a parameter very sensitive to the nanomaterials' organization and it also allows understanding the intermolecular interaction between polymer matrix and nanoparticles forces, which will promote better dispersion and distribution of the clay lamellae in the polymer matrix. Generally speaking, when exfoliation processes are predominant, the value of proton spin-lattice relaxation time decreases in relation to the polymer matrix. This happens because of the paramagnetic metals present in the clay lamellae. In this process the polymer molecules are around one clay lamellae, and the paramagnetic metals act as a relaxing agent. In contrast, when the intercalation process is predominant, the values of this parameter increase compared to the polymer matrix, due to the fact that the polymer chains have their movements constrained among clay lamellae, being not free to move [18]-[24].

\section{Experimental}

\subsection{Materials}

Commercial EVA containing $28 \mathrm{wt} \%$ VA was supplied by Polietilenos União (Brazil). The organoclay types (Viscogel S7 ${ }^{\circledR}$ and Viscogel S4 ${ }^{\circledR}$ ) were supplied by Bentec-Laviosa (Italy). These nanoparticles are organomodified montmorillonite clays. Information on their intercalating agents is presented in Table 1. 
Table 1. Organoclays employed as nanoparticles and their respective interlayer agents.

\begin{tabular}{|c|c|c|}
\hline Organoclays & Interlayer Agent & Interlayer Agent's Chemical Structure \\
\hline Viscogel $^{\circledR} \mathrm{S} 4$ & $\begin{array}{l}\text { Bis(Hydrogenated Tallow Alkyl) } \\
\text { Dimethyl Ammonium } \\
\text { (BHTADMA) }\end{array}$ & $\mathrm{R}-\left.\right|_{\mathrm{CH}_{3}} ^{\mathrm{CH}_{3}^{+}-\mathrm{R}}$ \\
\hline Viscogel $^{\circledR}$ S7 & $\begin{array}{l}\text { Dimethyl Benzyl Hydrogenated } \\
\text { Tallow Ammonium } \\
\text { (DMBHTA) }\end{array}$ & $-\left.\right|_{\mathrm{CH}_{3}} ^{\mathrm{N}^{+}-\mathrm{CH}_{2}-\left(\mathrm{CH}_{2}\right)_{12-16}-\mathrm{CH}_{3}}$ \\
\hline
\end{tabular}

\subsection{Nanocomposite Preparation}

All nanocomposites were prepared by solution casting using 1,1,2,2 tetrachloroethane (TCE) as solvent. A weighed amount of EVA ( $4 \mathrm{~g})$ was dissolved under stirring and then refluxed in TCE $(35 \mathrm{~mL})$ at $70^{\circ} \mathrm{C}$. The nanoclay dispersions of varying concentrations $(1,3$ and $5 \mathrm{wt} \%)$ were prepared in the same solvent $(5 \mathrm{~mL})$ under stirring for $1 \mathrm{~h}$ at room temperature. These dispersions were then added to the polymer solutions and stirring was continued for $1 \mathrm{~h}$ at $70^{\circ} \mathrm{C}$. Finally, a portion of each final solution was poured into a Petri dish and kept in an oven at $50^{\circ} \mathrm{C}$ for 5 days to eliminate the solvent.

\subsection{Thermogravimetric Analysis}

The thermal stability of the EVA nanocomposites was investigated by thermogravimetric analysis, using a TA Instruments Q500 thermogravimetric analyzer with precision of $\pm 1^{\circ} \mathrm{C}$, in order to determine the decomposition profile of the material. The measurements were obtained by heating the samples from $40^{\circ} \mathrm{C}$ to $600^{\circ} \mathrm{C}$ at a rate of $10^{\circ} \mathrm{C} /$ min under continuous flow of nitrogen.

\subsection{Differential Scanning Calorimetry}

The DSC analyses were carried out using a TA Instruments Q1000 calorimeter (with temperature accuracy of $\pm 0.1^{\circ} \mathrm{C}$ ) under a nitrogen flow rate of $50 \mathrm{~mL} / \mathrm{min}$. The temperature range for the test was from $-80^{\circ} \mathrm{C}$ to $250^{\circ} \mathrm{C}$, with heating and constant cooling at $10^{\circ} \mathrm{C} / \mathrm{min}$. The thermal transitions and crystallinity of EVA were evaluated after subjection to a second heating ramp designed to remove the effect of prior thermal history. Percentage crystallinity was calculated using the following equation:

$$
X c(\%)=\frac{\Delta H_{m}}{\Delta H_{100}} \times 100
$$

where $\Delta \mathrm{Hm}$ is the specific enthalpy of fusion for the studied composite and $\Delta \mathrm{H}_{100}$ is the specific enthalpy of fusion for $100 \%$ crystalline polyethylene $\left(\Delta \mathrm{Hm}, 293 \mathrm{~J}^{-1}{ }^{-1}\right)[21][25]$.

\subsection{X-Ray Diffraction}

XRD was performed using a Rigaku diffractometer with $\mathrm{CuK} \alpha$ radiation generator $(\lambda=0.154 \mathrm{~nm}, 40 \mathrm{Kv}, 120$ $\mathrm{mA}$ ) at room temperature, scanning over the $2 \theta$ range from $2^{\circ}$ to $40^{\circ}$ in $0.05^{\circ}$ steps, at a rate of $1 \% \mathrm{~min}$.

\subsection{NMR Relaxometry}

A Maran Ultra 23 low-field NMR spectrometer (Oxford Instruments), operating at $23 \mathrm{MHz}$ (for protons) and equipped with an $18 \mathrm{~mm}$ NMR tube was used to determine proton spin-lattice relaxation times $\left(\mathrm{T}_{1} \mathrm{H}\right)$. The pulse sequence used was inversion-recovery (recycle delay- $180^{\circ}-\tau-90^{\circ}$ acquisition data) and the $90^{\circ}$ pulse of $4.5 \mu \mathrm{s}$ was calibrated automatically by the software supplied with the instrument. The amplitude of the FID was sampled for $20 \tau$ data points, ranging from $0.01 \mathrm{~ms}$ to $10.0000 \mathrm{~ms}$; using 40 data points with 4 scans for each point and $5 \mathrm{~s}$ of recycle delay. The relaxation values were obtained by fitting the exponential data with the aid of the 
WINFIT program, and the domain distribution was obtained by the WINDXP software. The equipment's precision is $\pm 2 \%$. The relaxation values were calculated employing the following equation:

$$
M_{o}=M_{z}\left(1-\exp ^{-\tau / T_{1}}\right)
$$

\section{Results and Discussion}

\subsection{Thermogravimetric Analysis}

The TG and DTG curves of the EVA/S4 and EVA/S7 nanocomposites with different nanoclay amounts are presented in Figure 1 and Figure 2, respectively. They show that the thermal degradation of EVA and its nanocomposites undergoes two stages. The first stage is attributed to deacylation, which corresponds to the elimination of acetic acid and the formation of double bonds. Radical and anionic beta-elimination mechanisms (scheme 1) have been proposed for this reaction. The second stage is the main-chain degradation [7] [9] [16] [26]. Table 2 shows the values of the temperature of initial weight loss (Ti) and the temperature of maximum weight loss rate (Tmax) found for EVA and its nanocomposites. The results showed that the introduction of both OMMT types into the EVA matrix caused a decrease in the thermal stability of the nanocomposites studied. The most critical result was found for EVA systems containing $5 \mathrm{wt} \%$ OMMT compared to the other EVA systems prepared with the same type of organoclay. The EVA/S7 5\% and EVA/S4 5\% presented reductions in the initial degradation temperature $\left(\mathrm{T}_{\mathrm{i}}\right)$ of $42^{\circ} \mathrm{C}$ and $27^{\circ} \mathrm{C}$, respectively, compared to the EVA. This behavior was expected and it is common in EVA nanocomposites prepared with OMMT, because during thermal degradation their deacylation is accelerated and may occur at lower temperatures than those for pure EVA, due to catalysis by the strongly acid sites created by thermal decomposition of the silicate modifier (intercalating agent) [7]. These sites are active when there is contact or interaction between the polymer and the silicate.

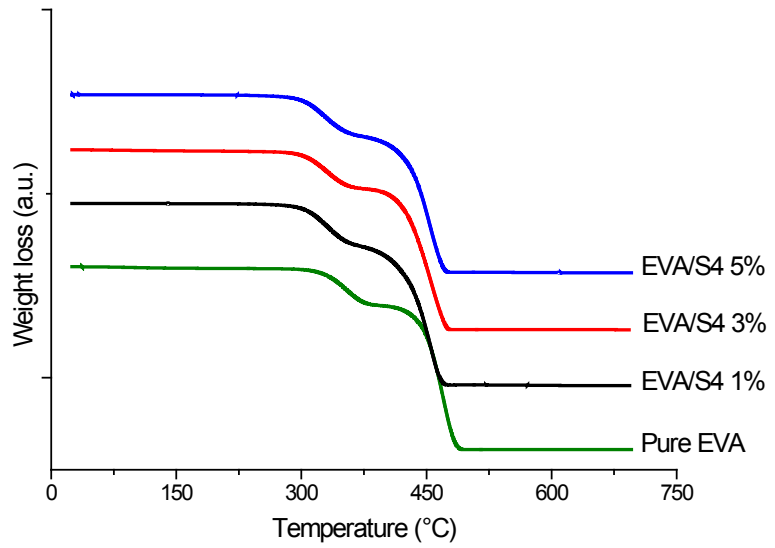

(a)

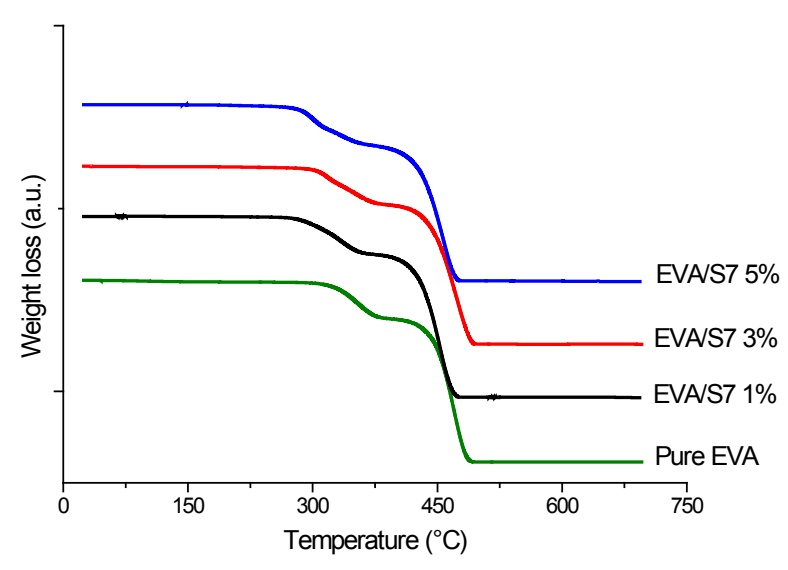

(b)

Figure 1. TG degradation curves for EVA/S4 (a) and EVA/S7 (b) systems with different nanoparticle ratios.

Table 2. Temperature of the initial weight loss $\left(\mathrm{T}_{\mathrm{i}}\right)$ and the temperature at which weight loss rate is maximum $\left(\mathrm{T}_{\max }\right)$ for the EVA copolymer and its nanocomposites.

\begin{tabular}{ccc}
\hline Samples & $\mathrm{T}_{\mathrm{i}}\left({ }^{\circ} \mathrm{C}\right)$ & $\mathrm{T}_{\max }\left({ }^{\circ} \mathrm{C}\right)$ \\
\hline EVA & 325 & 447 \\
EVA/S4 1\% & 304 & 430 \\
EVA/S4 3\% & 306 & 428 \\
EVA/S4 5\% & 298 & 428 \\
EVA/S7 1\% & 295 & 431 \\
EVA/S7 3\% & 303 & 443 \\
EVA/S7 5\% & 283 & 431 \\
\hline
\end{tabular}




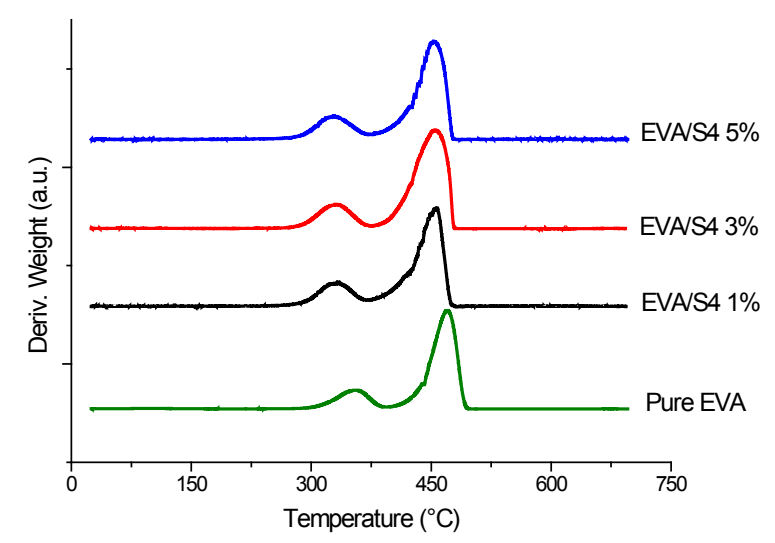

(a)

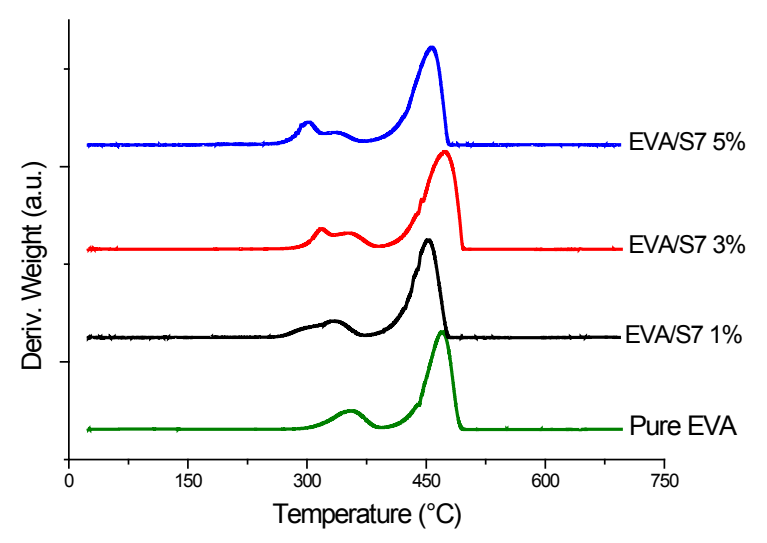

(b)

Figure 2. DTG curves for EVA/S4 (a) and EVA/S7 (b) systems with different nanoparticle ratios.

\subsection{Differential Scanning Calorimetry}

The DSC analyses were performed to monitor the effect of adding two different OMMTs on the thermal transition temperatures and also to evaluate the degree of crystallinity from the EVA matrix. Table 3 shows the values found for all thermal parameters studied. According to the results obtained from DSC (Table 3), addition of both OMMT types caused no significant change in the thermal transitions temperatures, meaning that the values found for glass transition temperature ( $\mathrm{Tg}$ ), melting temperature $(\mathrm{Tm})$ and crystallization temperature $(\mathrm{Tc})$ of the EVA nanocomposites prepared were similar to those obtained for EVA copolymer. In contrast, crystallinity data indicated that the addition of nanoparticles in the EVA matrix altered the crystallinity profile of some of the systems. The data reported in Table 3 show that the EVA/S7 systems had a tendency for declining crystallinity with increasing OMMT ratio. For these systems, the crystallinity of the formulation containing $5 \mathrm{wt} \%$ nanoparticles was $32 \%$ lower than for the EVA. This tendency was not observed for the EVA/S4 systems, although the one containing $5 \mathrm{wt} \%$ nanoparticles had $21 \%$ lower crystallinity comparing to EVA. These results indicate that the $5 \mathrm{wt} \%$ proportion of both nanoparticles caused the most pronounced changes in the EVA matrix, by preventing the packing of the molecules to form crystals.

\subsection{X-Ray Diffraction}

The X-ray diffractograms obtained from the two OMMT samples and their corresponding nanocomposites are shown in Figure 3. Table 4 presents the characteristics of the clays used in this study. XRD patterns supply very useful information on the gallery size of the final intercalated hybrids by measuring the increase of the basal (001) $d$-spacing [27].

From Figure 3 it is possible to observe that the EVA/S4 and EVA/S7 systems presented a heterogeneous structure, where a part of these systems was intercalated and the other one was aggregated. The presence of the intercalated portion was identified from the shift in the d001 peak to lower angles, indicating an increase in basal distance as a consequence of the interpenetration of polymeric chains inside the OMMT lamellae, but the d001 peak also appeared in the same position found for the OMMTs, showing the existence of an aggregated portion (Figure 3(a) and Figure 3(b)). Comparing the materials prepared with the two OMMT types, it was possible to observe that the EVA/S4 systems presented more significant decrease in intensity of d001 peak than the EVA/S7 systems, indicating better nanoparticle dispersion. This behavior was expected because the intercalating agent of the S7 clay has aromatic rings in its structure (Table 1), which are not chemically compatible with EVA.

For the systems studied in this work, the XRD results show that the intercalating agent of the clay was an important factor for the performance of the materials formed.

\subsection{NMR Relaxometry}

NMR relaxometry data can provide important insight into the molecular structure of systems containing nanoparticles [22]. Both OMMT clays used in this study (Viscogel S4 and Viscogel S7) caused a small decrease in 


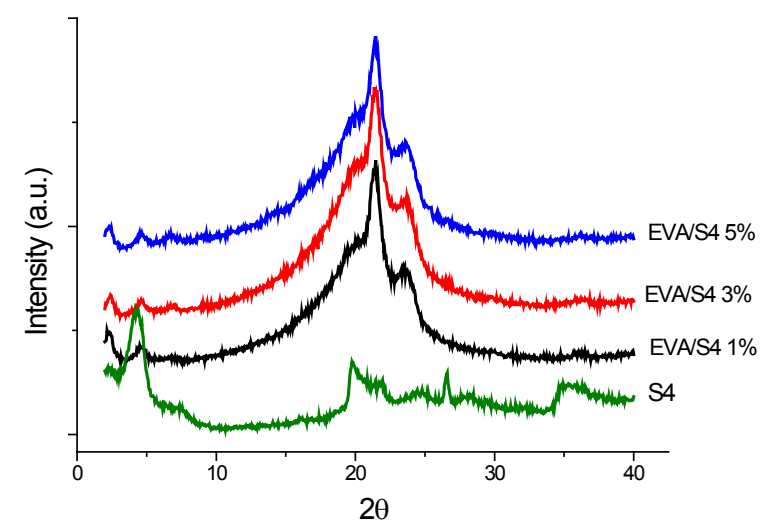

(a)

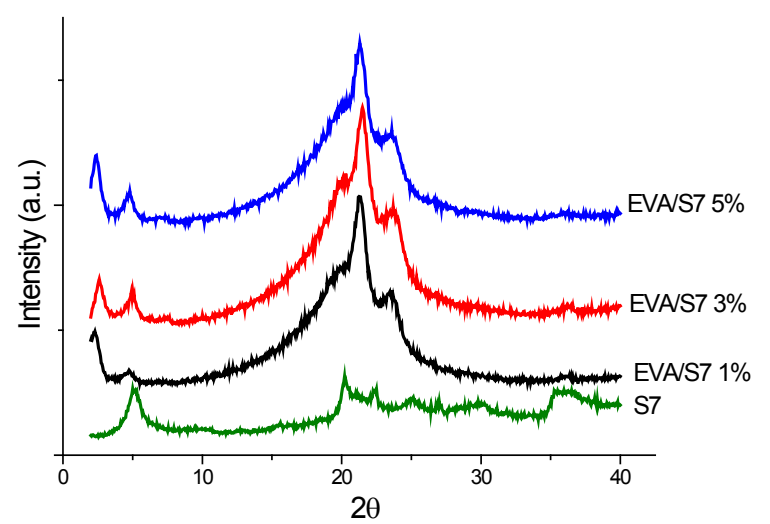

(b)

Figure 3. XDR patterns for EVA/S4 and EVA/S7 systems with different nanoparticle ratios.

Table 3. Thermal parameters and crystallinity degree obtained by DSC.

\begin{tabular}{|c|c|c|c|c|c|c|}
\hline Samples & $\operatorname{Tg}\left({ }^{\circ} \mathrm{C}\right)$ & $\operatorname{Tc}\left({ }^{\circ} \mathrm{C}\right)$ & $\Delta \mathrm{Hc}(\mathrm{J} / \mathrm{g})$ & $\operatorname{Tm}\left({ }^{\circ} \mathrm{C}\right)$ & $\Delta \mathrm{Hm}(\mathrm{J} / \mathrm{g})$ & Xc $(\%)$ \\
\hline EVA & -24 & 52 & 72 & 74 & 42 & 14 \\
\hline EVA/S4 1\% & -23 & 52 & 42 & 73 & 36 & 12 \\
\hline EVA/S4 3\% & -25 & 52 & 57 & 73 & 42 & 14 \\
\hline EVA/S4 5\% & -26 & 52 & 48 & 74 & 33 & 11 \\
\hline EVA/S7 1\% & -24 & 52 & 83 & 73 & 41 & 14 \\
\hline EVA/S7 3\% & -24 & 52 & 44 & 73 & 31 & 11 \\
\hline EVA/S7 5\% & -23 & 52 & 47 & 73 & 26 & 9 \\
\hline
\end{tabular}

Table 4. Characteristics of the clays used in this study.

\begin{tabular}{ccc} 
Sample & $2 \theta$ Peak & Basal Distance (nm) \\
\hline S4 & 3.95 & 2.23 \\
S7 & 5.00 & 1.76 \\
\hline
\end{tabular}

the proton relaxation times $\left(\mathrm{T}_{1} \mathrm{H}\right)$ of the EVA nanocomposites compared to EVA (Table 5). This phenomenon is expected when there is good interaction between the system components, generated in this case by the presence of an exfoliated phase in the material that makes possible the presence of molecular chains around the clay lamellae, promoting good dispersion/distribution of nanoparticles in the polymeric matrix. The decrease of $\mathrm{T}_{1} \mathrm{H}$ values occurs because of the presence of the paramagnetic metals in the clay lamellae, which influences the proton relaxation time, promoting changes in the chains' molecular mobility. This phenomenon is reflected in the $\mathrm{T}_{1} \mathrm{H}$ values, which give an idea of distribution of the clay lamellae, through the time that a proton system takes to recover (relax) to its original position state after being submitted to a radiofrequency. These results are in accordance with the findings of other studies [18]-[24].

The decrease in the $\mathrm{T}_{1} \mathrm{H}$ values was more pronounced in the EVA/clay nanocomposites containing $5 \mathrm{wt} \%$ of OMMTs, independent of the clay surfactant type, which means that the polymer/nanoparticle ratio together to the mixing method (solution intercalation) were more important than surfactant's structure. This result can be seen in Table 5 and also in Figure 4, where the distribution curves for EVA/S4 5\% and EVA S7 5\% systems present a more pronounced displacement. The lower relaxation times indicate that this proportion of the Viscogel S4 and Viscogel S7 nanoparticles was predominantly exfoliated. The most significant changes in the EVA matrix containing $5 \mathrm{wt} \%$ of both OMMT types were also observed by the DSC investigation, which indicated greater reduction in crystallinity, and also in TGA analysis, which showed a more pronounced decrease in thermal stability of these systems. The results obtained from NMR relaxometry were complementary to the XDR results and allowed the conclusion that EVA/S4 5\% and EVA/S7 5\% systems presented a multiphase structure with polymer intercalated in the clay lamellae and also a predominance of exfoliated OMMT clays in the EVA matrix. 


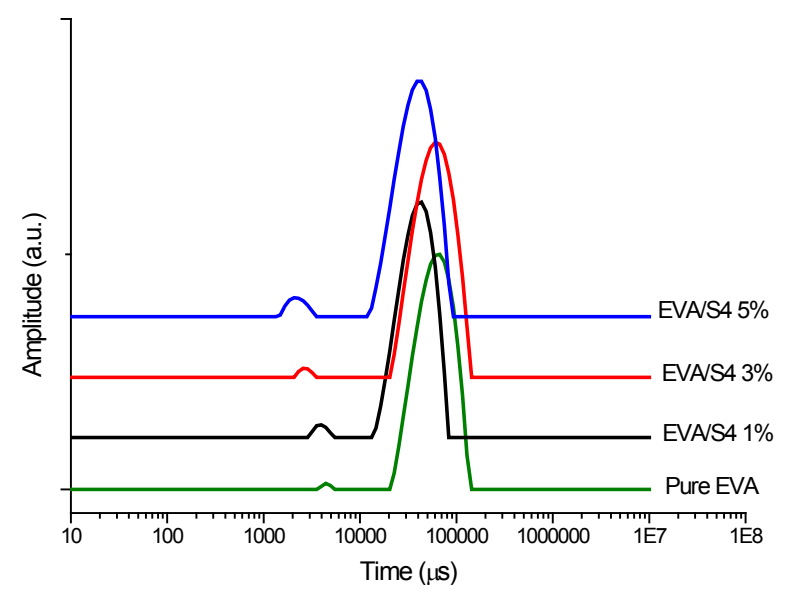

(a)

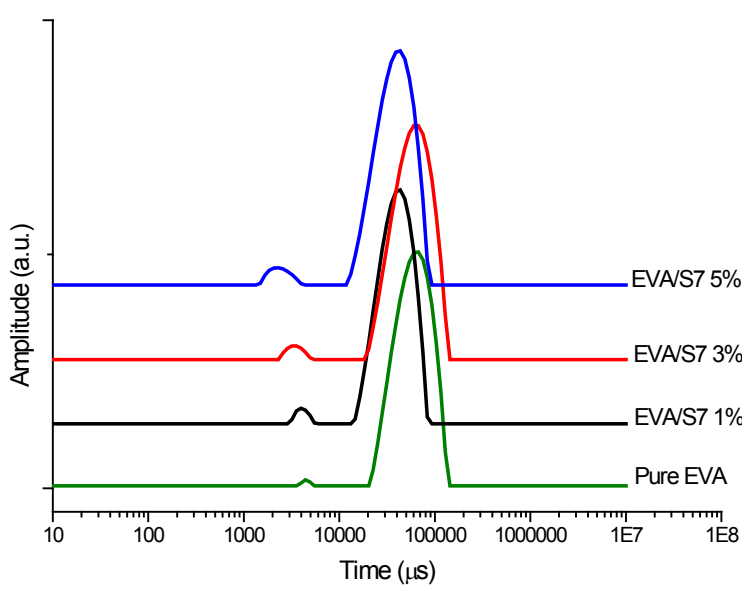

(b)

Figure 4. Domain curves for EVA/S4 (a) and EVA/S7 (b) with different nanoparticle ratios.

Table 5. $\mathrm{T}_{1} \mathrm{H}$ values for EVA and its nanocomposites.

\begin{tabular}{ccc}
\hline Samples & $\mathrm{T}_{1} \mathrm{H}(\mathrm{ms})$ \\
\hline EVA & 58 \\
EVA/S4 1\% & 56 \\
EVA/S4 3\% & 57 \\
EVA/S4 5\% & 53 \\
EVA/S7 1\% & 56 \\
EVA/S7 3\% & 55 \\
EVA/S7 5\% & 53 \\
\hline
\end{tabular}

\section{Conclusion}

The data obtained in the present study showed that the proposed solution intercalation method allowed obtaining nanostructured films with both OMMT clays used and also that the characterization techniques applied were effective for thermal and structural characterization. The thermal evaluation indicated a slight decrease on the degradation temperature and no change on the transition temperatures for the studied systems. In addition, a more pronounced change in the crystallinity profile was observed for the systems with $5 \mathrm{wt} \%$ OMMT. The structural characterization by XDR showed that partly intercalated nanocomposites were formed. On the other hand, the parameters obtained by spin-lattice relaxation time of hydrogen, $\mathrm{T}_{1} \mathrm{H}$, provided important and complementary information for the X-ray diffraction, due to the measurements' sensitivity and range of observation, showing that both systems prepared with $5 \mathrm{wt} \%$ OMMT presented a multiphase structure, with aggregated and intercalated portion and also an exfoliated phase.

\section{References}

[1] Almeida, A.S., Tavares, M.I B., Silva, E.O., Neto, R.P.C. and Moreira, L.A. (2012) Development of Hybrid Nanocomposites Based on PLLA and Low-Field NMR Characterization. Polymer Testing, 31, 267-275. http://dx.doi.org/10.1016/i.polymertesting.2011.11.005

[2] Tavares, M.I.B., Nogueira, R.F., Gil, R.A.S.S., Preto, M., Silva E.O., Silva, M.B.R. and Miguez, E. (2007) Polypropylene-Clay Nanocomposite Structure Probed by H NMR Relaxometry. Polymer Testing, 26, 1100-1102. http://dx.doi.org/10.1016/j.polymertesting.2007.07.012

[3] Esteves, A.C.C., Timmons, A.B. and Trindade, T. (2004) Nanocompósitos de matriz polimérica: Estratégias de síntese de materiais híbridos. Química Nova, 27, 798-806. http://dx.doi.org/10.1590/S0100-40422004000500020 
[4] Oliveira, M.F.L., Oliveira, M.G. and Leite M.C.A.M. (2011) Nanocompósitos de poliamida 6 e argila organofílica: Estudo da cristalinidade e propriedades mecânicas. Polímeros, 21, 78-82. http://dx.doi.org/10.1590/S0104-14282011005000015

[5] Palacios, J., Perera, R., Rosales, C., Albano, C. and Pastor, J.M. (2012) Thermal Degradation Kinetics of PP/OMMT Nanocomposites with mPE and EVA. Polymer Degradation and Stability, 97, 729-737. http://dx.doi.org/10.1016/j.polymdegradstab.2012.02.009

[6] Rodrigues, T.C., Tavares, M.I.B., Soares, I.L. and Moreira, A.M. (2009) The Characterization of High-Density Polyethylene/Organoclay Nanocomposites. JOM, 61, 38-41. http://dx.doi.org/10.1007/s11837-009-0006-x

[7] Zanetti, M., Caminoa, G., Thomannb, R. and Mülhaupt, R. (2001) Synthesis and Thermal Behaviour of Layered Silicate-EVA Nanocomposites. Polymer, 42, 4501-4507. http://dx.doi.org/10.1016/S0032-3861(00)00775-8

[8] Hussain, F., Hojjati, M., Okamoto, M. and Gorga, R.E. (2006) Review Article: Polymer-Matrix Nanocomposites, Processing, Manufacturing, and Application: An Overview. Journal of Composite Materials, 40, 1511-1575. http://dx.doi.org/10.1177/0021998306067321

[9] Silva, P.S.R.C. and Tavares, M.I.B. (2015) Solvent Effect on the Morphology of Lamellar Nanocomposites Based on HIPS. Materials Research, 18, 191-195. http://dx.doi.org/10.1590/1516-1439.307314

[10] Valera-Zaragoza, M., Ramírez-Vargas, E., Medellín-Rodríguez, F.J. and Huerta-Martínez, B.M. (2006) Thermal Stability and Flammability Properties of Heterophasic PP-EP/EVA/Organoclay Nanocomposites. Polymer Degradation and Stability, 91, 1319-1325. http://dx.doi.org/10.1016/j.polymdegradstab.2005.08.011

[11] Beltrán, M.I., Benavente, V., Marchante, V. and Marcilla, A. (2013) The Influence of Surfactant Loading Level in a Montmorillonite on the Thermal, Mechanical and Rheological Properties of EVA Nanocomposites. Applied Clay Science, 83-84, 153-161. http://dx.doi.org/10.1016/j.clay.2013.08.028

[12] Fereidoon, A., Memarian, S., Albooyeh, A. and Tarahomi, S. (2014) Influence of Mesoporous Silica and Hydroxyapatite Nanoparticles on the Mechanical and Morphological Properties of Polypropylene. Materials \& Design, 57, 201210. http://dx.doi.org/10.1016/j.matdes.2013.12.046

[13] Domenech, T., Peuvrel-Disdier, E. and Vergnes, B. (2013) The Importance of Specific Mechanical Energy during Twin Screw Extrusion of Organoclay Based Polypropylene Nanocomposites. Composites Science and Technology, 75, 7-14. http://dx.doi.org/10.1016/j.compscitech.2012.11.016

[14] Yang, M., Gao, Y., He, J.P. and Li, H.M. (2007) Preparation of Polyamide 6/Silica Nanocomposites from Silica Surface Initiated Ring-Opening Anionic Polymerization. eXPRESS Polymer Letters, 1, 433-442. http://dx.doi.org/10.3144/expresspolymlett.2007.61

[15] Youssef, A.M. and Abdel-Aziz, M.S. (2013) Preparation of Polystyrene Nanocomposites Based on Silver Nanoparticles Using Marine Bacterium for Packaging. Polymer-Plastics Technology and Engineering, 52, 607-613. http://dx.doi.org/10.1080/03602559.2012.762658

[16] Zhang, W., Chen, D., Zhao, Q. and Fang, Y. (2003) Effects of Different Kinds of Clay and Different Vinyl Acetate Content on the Morphology and Properties of EVA/Clay Nanocomposites. Polymer, 44, 7953-7961. http://dx.doi.org/10.1016/j.polymer.2003.10.046

[17] Papon, A., Saalwächter, K., Schäler, K., Guy, L., Lequeux, F. and Montes H. (2011) Low-Field NMR Investigations of Nanocomposites: Polymer Dynamics and Network Effects. Macromolecules, 44, 913-922. http://dx.doi.org/10.1021/ma102486x

[18] Passos, A.A., Tavares, M.I.B., Neto, R.C.P., Moreira, L.A. and Ferreira, A.G. (2011) Obtenção de nanocompósito de EVA/sílica e caracterização por ressonância magnética nuclear no estado sólido. Polímeros, 21, 98-102. http://dx.doi.org/10.1590/S0104-14282011005000023

[19] Silva, E.O., Tavares, M.I.B. and Nogueira, J. (2008) Solid State NMR Evaluation of Natural Resin/Clay Nanocomposites. Journal of Nano Research, 4, 117-126. http://dx.doi.org/10.4028/www.scientific.net/JNanoR.4.117

[20] Merat, P.P., Tavares, M.I.B. and Silva, E.O. (2011) Preparation of Polycarbonate/Clay Nanocomposite and Characterization by X-Ray, Thermal Analyzes and Low-Field Nuclear Magnetic Resonance. Journal of Materials Science and Engineering, 1, 671-677.

[21] Valentim, A.C.S., Tavares, M.I.B. and Silva, E.O. (2014) Effect of Adding $\mathrm{TiO}_{2}$ to Ethylene Vinyl Acetate Copolymer on the Latter's Thermal Properties and Crystallinity. Química Nova, 37, 255-259. http://dx.doi.org/10.5935/0100-4042.20140044

[22] Rodrigues, T.C., Tavares, M.I.B., Preto, M., Soares, I.L. and Moreira, A.C.F. (2008) Evaluation of Polyethylene/Organoclay Nanocomposites by Low-Field Nuclear Relaxation. International Journal of Polymeric Materials, 57, 11191123. http://dx.doi.org/10.1080/00914030802428716

[23] VanderHart, D.L., Asano, A. and Gilman, J.W. (2001) Solid-State NMR Investigation of Paramagnetic Nylon-6 Clay Nanocomposites. 1. Crystallinity, Morphology, and the Direct Influence of $\mathrm{Fe}^{3+}$ on Nuclear Spins. Chemistry of Mate- 
rials, 13, 3781-3795. http://dx.doi.org/10.1021/cm0110775

[24] VanderHart, D.L., Asano, A. and Gilman, J.W. (2001) Solid-State NMR Investigation of Paramagnetic Nylon-6 Clay Nanocomposites. 2. Measurement of Clay Dispersion, Crystal Stratification, and Stability of Organic Modifiers. Chemistry of Materials, 13, 3796-3809. http://dx.doi.org/10.1021/cm011078x

[25] Preston, C.M., Amarasinghe, G., Hopewell, J.L., Shanks, R.A. and Mathys, Z. (2004) Evaluation of Polar Ethylene Copolymers as Fire Retardant Nanocomposite Matrices. Polymer Degradation and Stability, 84, 533-544. http://dx.doi.org/10.1016/j.polymdegradstab.2004.02.004

[26] Camino, G., Sgobbi, R., Zaopo, A., Colombier, S. and Scelza, C. (2000) Investigation of Flame Retardancy in EVA. Fire and Materials, 24, 85-90. http://dx.doi.org/10.1002/1099-1018(200003/04)24:2<85::AID-FAM724>3.0.CO;2-T

[27] Shen, Z., Simon, G.P. and Cheng, Y.-B. (2002) Comparison of Solution Intercalation and Melt Intercalation of Polymer-Clay Nanocomposites. Polymer, 43, 4251-4260. http://dx.doi.org/10.1016/S0032-3861(02)00230-6 